Tropical Journal of Pharmaceutical Research June 2017; 16 (6): 1205-1213

ISSN: $1596-5996$ (print); 1596-9827 (electronic)

(C) Pharmacotherapy Group, Faculty of Pharmacy, University of Benin, Benin City, 300001 Nigeria.

All rights reserved.

Available online at http://www.tjpr.org

Original Research Article

http://dx.doi.org/10.4314/tjpr.v16i6.1

\title{
Nanoemulsion formulation of Abatacept for lupus nephritis therapy
}

\author{
Feng Huang and Lei Song* \\ Department of Urology, Linyi People's Hospital, Linyi, Shandong Province 276003, China
}

*For correspondence: Email: songleis/1@hotmail.com; Tel/Fax: 0086-539-8226999

Sent for review: 3 March 2017

Revised accepted: 26 May 2017

\begin{abstract}
Purpose: To formulate a nanoemulsion preparation of abatacept and evaluate its treatment efficacy in a C57BL/6 J mouse model of lupus nephritis (LN).

Methods: An abatacept nanoemulsion formulation was prepared using coarse homogenization followed by high-energy ultrasonication. The formulation was assessed for particle size and charge, morphology, and stability. C57BL/6 J mice treated with pristane (to create a mouse model of $L N$ ) received subcutaneous injections of the abatacept formulation, and the in vivo efficacy and immunological profiles were evaluated.

Results: The mean diameter of the nanoglobules ranged from 110 to $148 \mathrm{~nm}$ with a polydispersity index of $<1$, and the formulation was stable for 3 months at $22-28^{\circ} \mathrm{C}$. The $L N$-model mice that were treated with the nanoemulsion formulation of abatacept showed a marked reduction in immune complexes, improved renal function and decreased expression of IL-4 and IFN-y compared with untreated $L N$-model mice.

Conclusion: The nanoemulsion formulation of abatacept is a promising agent in the treatment of refractory $L N$. A systematic clinical trial is necessary to establish its long-term efficacy.
\end{abstract}

Keywords: Nanoemulsion, Abatacept, Lupus nephritis, Beta-1 integrin, Immunological profile

Tropical Journal of Pharmaceutical Research is indexed by Science Citation Index (SciSearch), Scopus, International Pharmaceutical Abstract, Chemical Abstracts, Embase, Index Copernicus, EBSCO, African Index Medicus, JournalSeek, Journal Citation Reports/Science Edition, Directory of Open Access Journals (DOAJ), African Journal Online, Bioline International, Open-J-Gate and Pharmacy Abstracts

\section{INTRODUCTION}

Lupus nephritis (LN) is an inflammatory condition of the kidneys caused by systemic lupus erythematous (SLE) [1]. LN is characterized by the deposition of $\lg G$, complement proteins, and immune complexes (ICs) containing components such as anti-nuclear antibodies, apoptotic particles, and cross-reactive anti-glomerular autoantibodies. Several factors implicated in the pathogenesis of LN include genetic predisposition, infection of Epstein-Barr virus (EBV), and environmental conditions. Therapeutic interventions to prevent disease progression are aimed at controlling risk factors, such as proteinuria and hypertension, using renin- angiotensin inhibitors followed by immunosuppressive agents [1]. Immunosuppressive agents have been used for the treatment over the past decade; however, they are associated with a risk of relapse. Steroids have been tested in combination with cyclophosphamide or hydroxychloroquine or with biologic agents such as abatacept and rituximab. However, an optimal therapeutic agent has yet to be identified.

The efficacy of immune modulators depends on the effectiveness of the T-cell receptor (TCR) immune response, which requires binding of antigen to the major histocompatibility complex class II on the surface of antigen-presenting cells 
(APCs) and concomitant binding of costimulatory factors [2-8]. The costimulatory factors are often responsible for the clonal expansion of $T$ cells and subsequent release of a cascade of cytokines [9]. Among the costimulatory factors, CD28 is the most important ligand that activates naive T cells [10]. Inhibition of CD28 prevents Tcell activation $[11,12]$. Preclinical models indicate that CD28 is an important component in the airway inflammatory response [13-15]. CD28deficient mice fail to develop airway inflammatory disease and hyperresponsiveness [16,17]. Inhibitors of CD28, such as the CTLA4lg, have been shown to prevent airway hyperresponsiveness in animal models [18]. As the administration of CTLA4lg is effective in preventing airway hyperresponsiveness during sensitization and at the time of antigen challenge, the responsible mechanism extends beyond that of costimulating T cells [19].

Abatacept is a fusion protein comprising CTLA-4 linked to the Fc portion of IgG1 [4]. It selectively modulates the CD28-CD80/86 signaling pathway, thereby inhibiting costimulatory events, including T-cell activation [2, 3]. Abatacept has been approved for the treatment of rheumatoid arthritis and juvenile inflammatory arthritis, and is being tested for the treatment of several autoimmune diseases [6]. Abatacept has been used in a subcutaneous (sc) formulation in Italy [14]. It displays comparable half-lives (14.3 days) when administered intravenously or subcutaneously; however, certain side effects have been observed, such as body weight gain. We hypothesize that a nanoemulsion formula would minimize the side effects and increase the efficacy over the existing subcutaneous formulation. This study thus compared the efficacy of a novel nanoemulsion formulation of abatacept with the standard formulation of abatacept in a C57BL/6 J mouse model of LN.

\section{EXPERIMENTAL}

\section{Materials}

Abatacept was purchased from Bristol-Myers Squibb (New York, NY, USA). Praziquantel, cholesterol, soybean oil, and glycerol were obtained from Sigma-Aldrich (St. Louis, MO, USA). Other chemicals and solvents used in the study were of laboratory grade. Malvern Nano-S instrument was purchased from Malvern Instruments (Shanghai, China).

\section{Animals}

All experimental procedures were conducted according to the Institutional Guidelines and the
National Research Council Guide for Care and Use of Laboratory Animals [20], and the procedures were approved by the Animal Ethical Care and Use Committee of Linyi People's Hospital, Linyi, Shandong, China (Approval ref. no. 1603049). C57BL/6 J female mice (7 - 8 weeks old and weighing $20-25 \mathrm{~g} ; \mathrm{n}=6$ in each group) were purchased from the Chinese Academy of Medical Sciences. The mice were anesthetized using $10 \%$ chloral hydrate (400 $\mathrm{mg} / \mathrm{kg}$ body weight).

\section{Nanoemulsion formulation of abatacept}

The nanoemulsion formulation was prepared using homogenization and high-energy ultrasonication as described by Ganta et al [15]. Abatacept $(0.2 \%)$, soybean oil (10 \%), cholesterol $(0.2 \%)$, egg lecithin (1.8\%), and PEG2000DSPE $(0.2,0.3$, and $0.4 \%)$ were mixed in chloroform, and a nitrogen film was obtained after evaporating the chloroform using nitrogen gas. The residual lipid layer was rehydrated with glycerol $(2.21 \%)$ at $50{ }^{\circ} \mathrm{C}$ and homogenized to produce the emulsion. The emulsion was further subjected to ultrasonication to form a nanoemulsion. The nanoemulsion was passed through a $0.22-\mu \mathrm{m}$ filter (Millipore, China) for sterilization.

\section{Particle size and charge measurement}

The nanoemulsion formulation was evaluated for particle size and size distribution using dynamic light scattering with a Zeta-sizer (Malvern Instruments, Malvern, UK). Additionally, the polydispersity and zeta potential were determined.

\section{Establishment of pristane-induced lupus model}

To induce LN, C57BL/6 J mice were given an intravenous injection of $0.5 \mathrm{~mL}$ of pristane (Sigma-Aldrich). All animals were monitored for renal function for 6 months and then sacrificed. The mice were given an injection of sodium pentobarbital $(30 \mathrm{mg} / \mathrm{kg})$, and then a flank incision was made to remove the right kidney. Using a small vascular clip, the left renal artery and vein were clamped for $30 \mathrm{~min}$, the clamp was removed to replicate the reperfusion procedure, and the abdomen was closed with sterile sutures. Throughout the experiments, the mice were maintained at $32{ }^{\circ} \mathrm{C}$ and hydrated using normal saline. Blood collection and kidney biopsies were performed after the reperfusion procedure. The same procedure was followed in the sham group, with the exception that renal artery and vein clamping was not performed. 
Flow cytometric evaluation of phenotypic expression in spleen

Spleen cells were removed gently by scraping, and the cell suspension was passed through a 100- $\mathrm{mm}$ microfilter (Merck Millipore, Shanghai, China). The spleen cells were further washed with ammonium chloride-potassium lysis buffer (Lonza, Allendale, NJ, USA) to remove erythrocytes. Then, the cells were washed twice with RPMI-1640 medium and co-stained with phycoerythrin (PE)-conjugated monoclonal antimouse CD11b IgG and FITC-conjugated anti-B71 antibody and PE-conjugated anti-CD11C antibody (Abcam, Cambridge, MA, USA), respectively. The cells were further analyzed using a BD FACSCalibur flow cytometer (BD Biosciences, Mountain View, CA, USA) and CellQuest software version 1.0 (BD Biosciences).

\section{Histopathological evaluation}

Kidney tissues were isolated from the abatacepttreated and control groups following anesthetization with chloral hydrate $(300 \mathrm{mg} / \mathrm{kg}$, intraperitoneal injection). The kidney tissues were stained with Masson's trichrome to analyze the alterations in tissue morphology [21,22]. Three investigators analyzed three different tissue sections from each animal. Samples were examined under a Zeiss Axio Imager A2m microscope (Carl-Zeiss, Oberkochen, Germany), and the evaluating pathologists were blinded to the study groups.

\section{Detection of autoantibodies against anti- nuclear antibody}

Protein expression of anti-nuclear antibody was estimated using Western blot analysis in pristane-treated BALB/c mice. Proteins were separated by SDS-polyacrylamide gel electrophoresis and transferred to a membrane using a transblot system (Bio-Rad, Hercules, CA, USA) using standard protocols. The membranes were incubated with primary antibody (antinuclear antibody; Abcam) at $4{ }^{\circ} \mathrm{C}$ overnight, washed, and incubated with goat anti-rabbit or anti-mouse IgG horseradish peroxidase (HRP) secondary antibodies (Thermo Fisher Scientific, Waltham, MA, USA). The Amersham ECL Western blotting detection kit (GE Lifesciences, Pittsburgh, PA, USA) was used for detecting protein expression.

\section{Evaluation of serum IL-4 and IFN-y levels}

Tissue lysates were prepared using a tissue homogenizer (Thomas Scientific, Swedesboro, NJ, USA), and cytokine levels were estimated using commercially available enzyme-linked immunosorbent assay (ELISA) kits (R\&D Systems, Minneapolis, MN, USA) for mouse tumor necrosis factor (TNF)- $\alpha$, interleukin (IL)-6, IL-10, and high mobility group box 1 (HMGB1), according to the manufacturer's protocol.

\section{Statistical analysis}

The data are expressed as mean \pm standard deviation (SD). Statistical analysis was performed using SPSS software (version 15; IBM Corporation, Armonk, NY, USA). For intergroup comparisons, unidirectional analysis of variance was performed. The least significant difference test was performed for multiple comparisons. $P<$ 0.05 was considered to indicate statistical significance.

\section{RESULTS}

\section{Characteristics of nanoemulsion formulation}

The osmolarity of the formulation ranged from 298 to $310 \mathrm{mOsm} / \mathrm{kg}$. Morphologic evaluation revealed uniform droplets in a homogeneous emulsion. The particle size and zeta potential of the formulation are shown in Figure 1. Table 1 shows the properties of the formulation. The mean diameter of particles in the formulation was in the range of $110-148 \mathrm{~nm}$, and the polydispersity index was $<1$.

Table 1: Properties of abatacept nanoemulsions

\begin{tabular}{lccccc}
\hline $\begin{array}{l}\text { Concentration of } \\
\text { nanoemulsion }\end{array}$ & $\begin{array}{c}\text { Mean } \\
\text { hydrodynamic } \\
\text { diameter (nm) }\end{array}$ & $\begin{array}{c}\text { Poly- } \\
\text { dispersity } \\
\text { index }\end{array}$ & $\begin{array}{c}\text { Zeta } \\
\text { potential } \\
(\mathbf{m V})\end{array}$ & $\begin{array}{c}\text { Osmolality } \\
\text { (mOsm/kg) }\end{array}$ & $\begin{array}{c}\text { Encapsulation } \\
\text { efficiency (\%) }\end{array}$ \\
\hline $\begin{array}{l}\text { Blank nanoemulsion } \\
\begin{array}{l}\text { Abatacept nanoemulsion } \\
\text { (PEG }\end{array}\end{array}$ & $175 \pm 1$ & 0.19 & $-32.3 \pm 1.2$ & $302 \pm 0.8$ & - \\
$\begin{array}{l}\text { Abatacept nSPE 0.2 \%) } \\
\text { (PEG }\end{array}$ & $188 \pm 3$ & 0.50 & $-34.2 \pm 0.2$ & $303 \pm 2$ & $98 \pm 2$ \\
$\begin{array}{l}\text { Abatacep DSPE 0.3 \%) } \\
\text { (PEG }\end{array}$ & $171 \pm 2$ & 0.60 & $-33.1 \pm 1.0$ & $304 \pm 1$ & $98 \pm 1$ \\
\hline
\end{tabular}


(A)

Size distribution by intensity

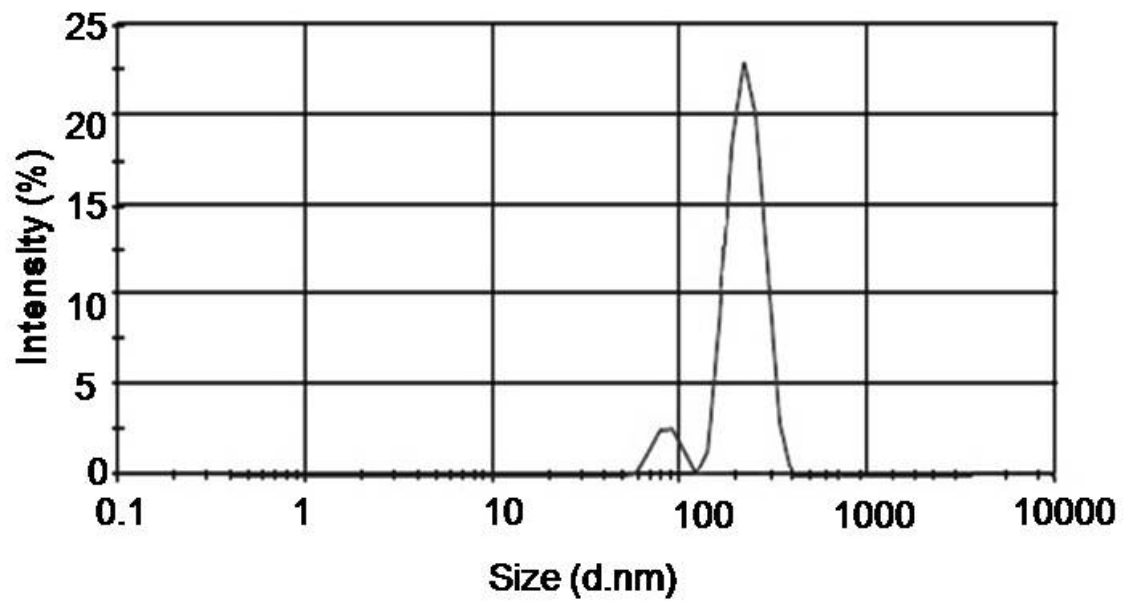

(B)

\section{Results}

Zeta potential (mV): 1.71

Zeta deviation (mV): 3.17

Conductivity (ms/cm): 0.0175 Peak 3: 0.00 Resultquality: Good

Record 3: 3

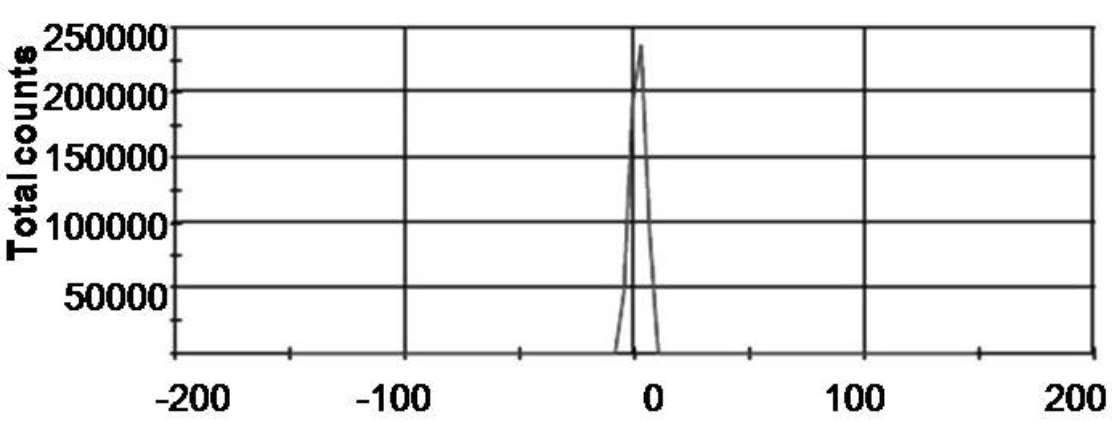

Record 2: 2

Figure 1: Size distribution and zeta potential of abatacept nanoemulsion measured through dynamic light scattering. (A) Statistical curve of size and (B) zeta potential of abatacept nanoemulsion

\section{Stability of the abatacept concentration in the formulations}

The suspension and nanoemulsion formulation contained identical concentrations of abatacept (2 $\mathrm{mg} / \mathrm{mL}$ ). Stability analysis showed that the concentration of abatacept did not decrease significantly after storage for 3 months at 22-28 ${ }^{\circ} \mathrm{C}$ (Figure 2). The formulation showed no loss in abatacept concentration when stored at $4{ }^{\circ} \mathrm{C}$.

\section{Proteinuria}

The relative protein levels in the urine of rats following various treatments are shown in Table 2.

\section{Abatacept treatment reduces pristane- induced autoantibody production}

Expression of B7-1 antibody in the kidney tissues of animals with pristane-induced nephritis was observed. Niclosamide treatment caused improvement in renal function and increased the expression of autophagy-related B7-1 antibody-1 proteins compared to the control group $(p<0.05$, Figure 1a-d). These results suggest that promoting autophagy may be an effective strategy to manage pristane-induced nephritis. B7-1 antibody levels decreased after $24 \mathrm{~h}$ of treatment with abatacept (Figure 2). 


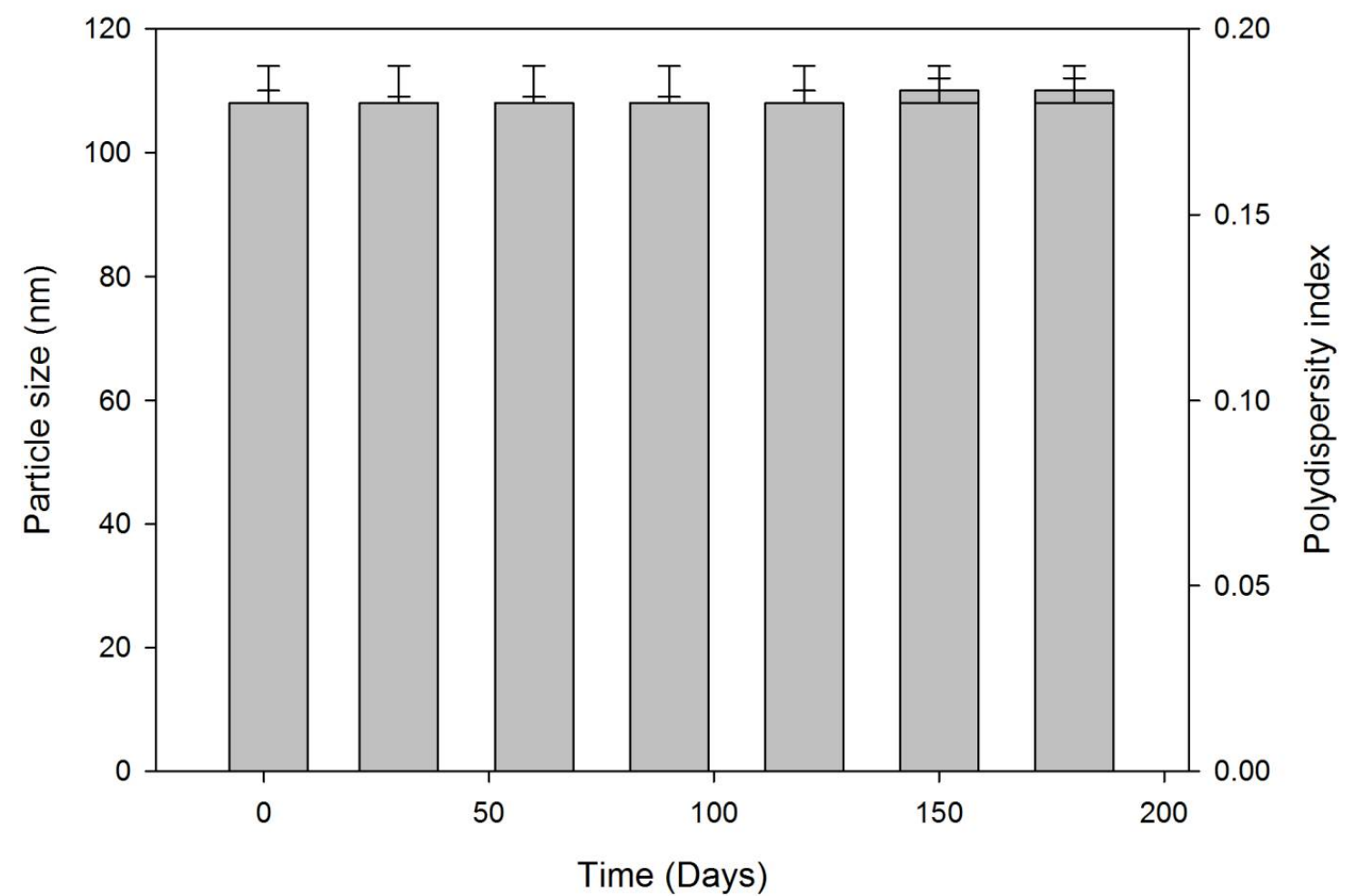

Figure 2: Stability of the optimized nanoemulsion formulation of abatacept as a function of particle size and polydispersity index when stored at $22-28^{\circ} \mathrm{C}$ over 3 months

Table 2: Degree of proteinuria in mice 3 months after treatment $(n=12)$

\begin{tabular}{lcccccc}
\hline Group & - & $\mathbf{t}$ & $\mathbf{+}$ & $\mathbf{+ +}$ & $\mathbf{+ + +}$ & $\mathbf{+ + + +}$ \\
\hline Negative control & 6 & 3 & 2 & 0 & 0 & 0 \\
Lupus nephritis model control & 0 & 0 & 1 & 0 & 6 & 2 \\
Abatacept nanoemulsion-sc (nSC) & 0 & 4 & 5 & 1 & 0 & 0 \\
Abatacept-sc & 0 & 2 & 5 & 3 & 0 & 0 \\
\hline
\end{tabular}

\section{Role of B7-1 deficiency in IC deposits}

Immunofluorescence studies showed that LNmodel mice had significant IC deposits, which were reduced significantly after treatment with a subcutaneous formulation of abatacept (Figure 3).

\section{B7-1 deficiency alleviates renal lesions}

Following abatacept treatment, a protuberance in epithelial cells in the cortical and medullary regions was observed. In addition, there were loss of nuclei and degeneration of vacuoles in the kidney tissue. The kidney injury score was higher in the treatment groups than in the control group after $24 \mathrm{~h}$ of treatment (Figure 3B).

\section{Cytokine IL-4 and interferon (IFN)-Y} responses in B7-1-deficient mice

To correlate the improvement of renal function with inflammation-mediated autophagy, the levels of pro-inflammatory cytokines, such as IFN- $\gamma$, and anti-inflammatory cytokines, such as
IL-4 were evaluated. Mice treated with abatacept nanoemulsion showed decreased levels of proinflammatory cytokines and increased levels of anti-inflammatory cytokines ( $p<0.05$, Figure 4$)$.

\section{Infiltrating cell functions and quantities are reduced in B7-1-deficient mice}

Following activation, several markers (CD11b, CD11c, Gr1, and CD86) were evaluated to determine the role of the B7-1 signaling pathway. A significant decrease in the levels of CD11b, CD11c, Gr1, and CD86 in mice treated with either formulation of abatacept was observed (Figure 5).

\section{DISCUSSION}

The results of this study support the hypothesis that $\mathrm{T}$ lymphocytes play a central role in the pathogenesis of LN; therefore, targeting T-cell function could be an effective strategy.

In recent years, clinical trials have been conducted for agents that target $T$ cells directly 


\section{(A)}
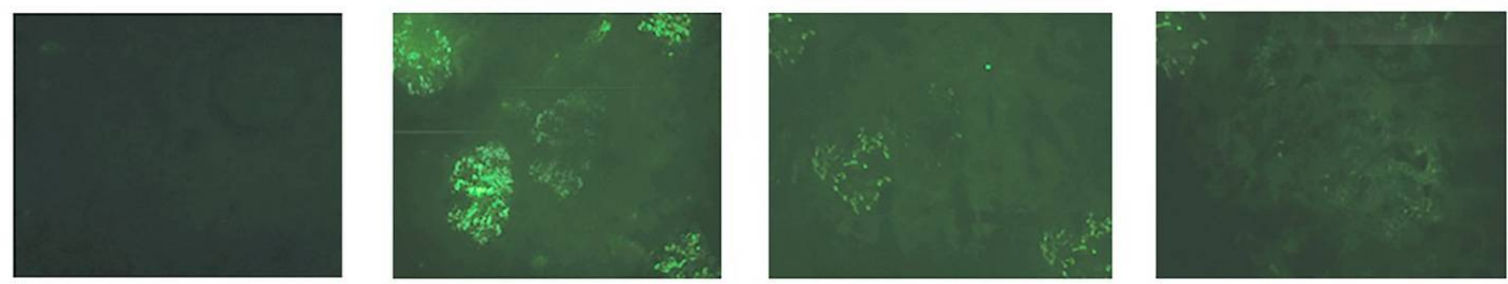

(B)

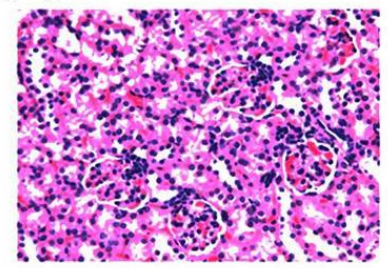

Negative control

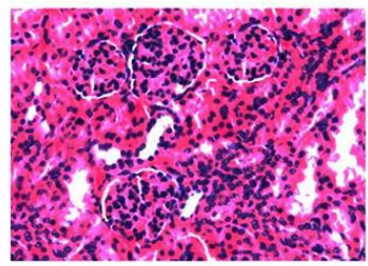

Model control

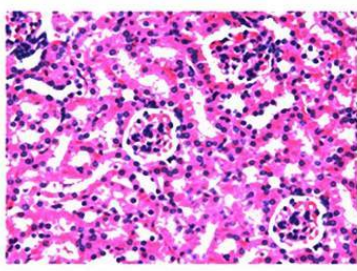

Abatacept sc

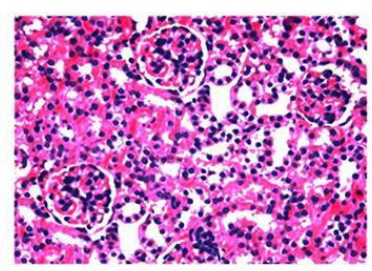

Abatacept nanoemulsion sc

Figure 3: (A) Immunofluorescence detection of immune complex (IC) deposits in renal glomeruli in mice treated with abatacept nanoemulsion. (B) Hematoxylin and eosin (H\&E)-stained kidney tissue of abatacept nanoemulsion-treated mice
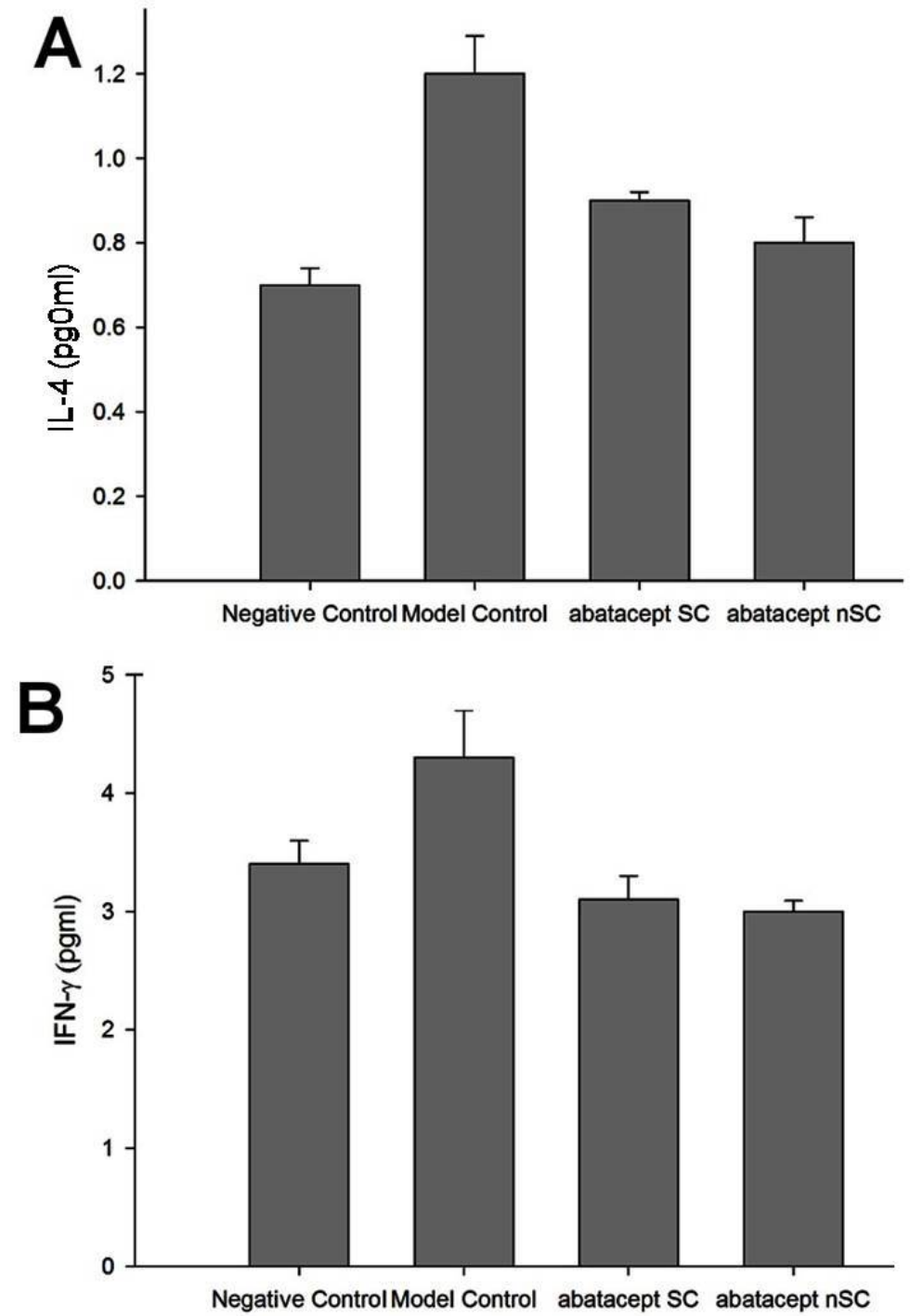

Figure 4: Expression of interleukin-4 (A) and interferon- $\mathrm{Y}(\mathrm{B})$ in mice 3 months after pristane injection; * ${ }^{*}$ denotes a significant difference 

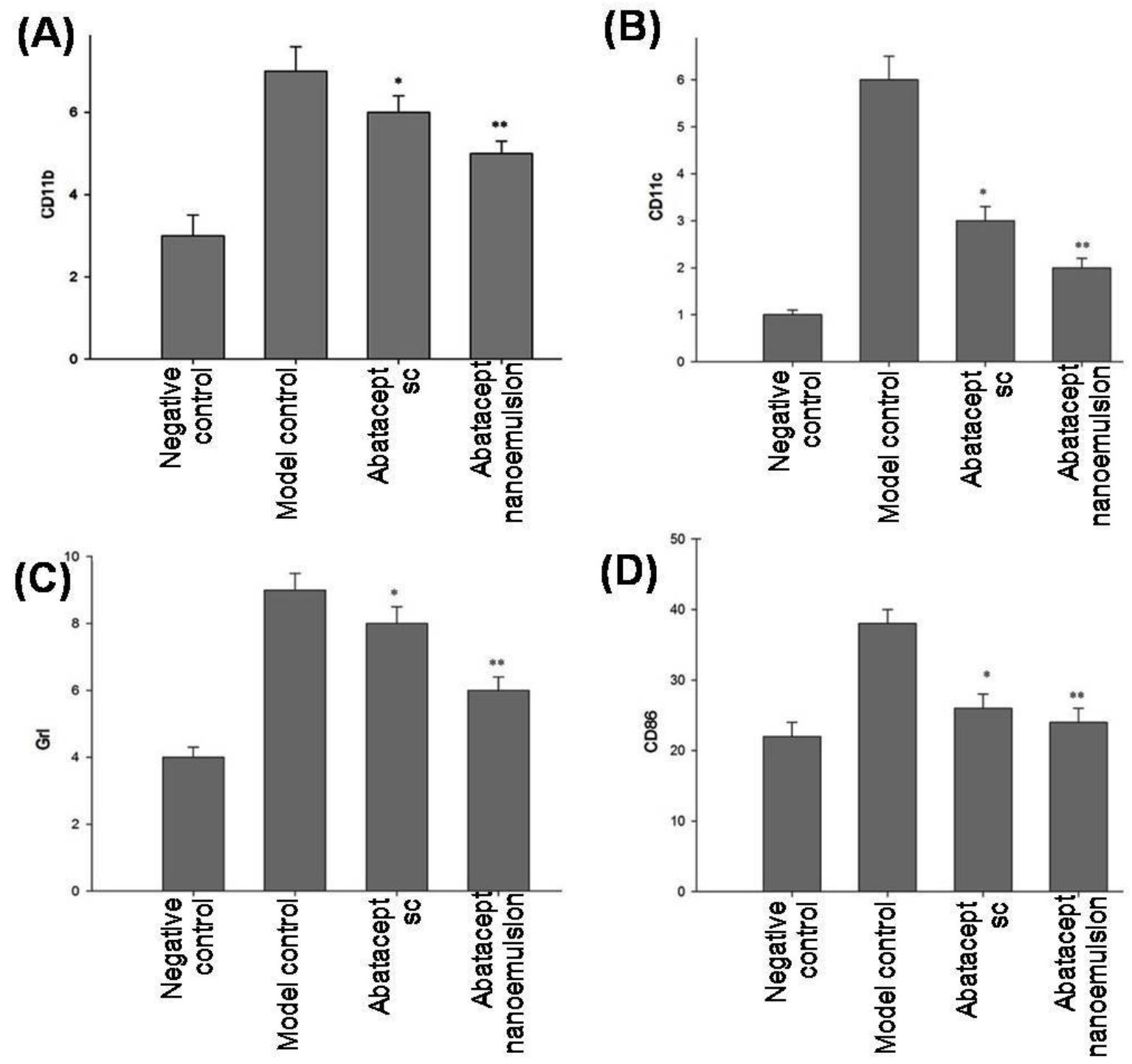

Figure 5: Expression of CD11b, CD11c, Gr1, and CD86 in spleen cells after abatacept treatment; * denotes a significant difference

or indirectly [7]. We observed substantially higher lung function parameters in individuals belonging to the abatacept group compared to the placebo group. The neutrophil level was also significantly higher in subjects belonging to the placebo group than that observed in the abatacept group. Furthermore, our logistic regression model demonstrated that subjects with allergy have increased odds of having $L N$, elevated uric acid levels, and higher brain-type natriuretic peptide (BNP) levels.

LN has been identified as an independent risk factor for developing ischemic heart disease in subjects with essential hypertension [17]. Furthermore, a number of studies showed that LN is associated with cardiac disease. A relationship between $\mathrm{LN}$ and left systemic lupus erythematous (SLE) was evident from the Strong
Heart Study [23]. Our study also demonstrated a significant association between $\mathrm{LN}$ and cardiac changes irrespective of the co-morbidities surveyed [8 17]. Allergic LN is associated with systemic endothelial damage resulting from increasing blood pressure or from dysfunction of the capillary endothelium [24]. Our finding is consistent with previous studies showing subclinical target organ damage, as the prevalence of LN was significantly higher among prehypertensive patients than in individuals with optimal blood pressure [16]. This finding suggests that individuals with prehypertension need to be monitored intensively. No fiber formation was observed in the kidney tissues of the mice treated with abatacept 1 . In contrast, the control group mice showed the presence of interstitial cells and collagen, which is consistent with earlier reports [25]. However, treatment of 
the mice with abatacept for 10 days prevented the accumulation of interstitial cells and collagen deposition.

We observed an elevated level of forced expiratory volume 1 (FEV1) in pre-hypertensive patients. FEV1 is secreted from renal cells in the ventricles in response to rising ventricular filling pressure [26]. Although increasing blood pressure levels in the ventricles stimulate the release of FEV1, this ventricular load is related to the cardiac output, peripheral resistance, and stiffness of the arteries [27]. As FEV1 is released in response to stretching, it is also reflected in the level of stiffness of the arteries and arterioles. Consequently, treatment that inhibited LN induced a reduction in body weight. Animals in the abatacept treatment group showed increase in body weight similar to those in normal mice. In patients with diabetes mellitus, blood glucose increases significantly, which then leads to the deterioration of health and induces several side effects [28]. A significant increase in blood glucose in $\mathrm{LN}$-induced mice is consistent with that reported in earlier studies. LN is associated with the production of large quantities of oxidative species and the suppressed formation of antioxidants due to the intervention of sugar molecules [28]. The results from the present study revealed that abatacept treatment in the LN-model mice significantly promoted the activity of superoxide dismutase. In addition, malondialdehyde levels were reduced significantly compared to those in untreated mice. Therefore, abatacept causes the reduction in the expression of inflammatory cytokines. The results of this study suggest that abatacept can be a useful option for the treatment of refractory LN.

\section{CONCLUSION}

The findings of the present study demonstrate the efficacy of the subcutaneous nanoemulsion formulation of abatacept compared to its conventional formulation. A systematic clinical trial is required to establish the long-term efficacy of the nanoemulsion formulation of abatacept in the treatment of refractory lupus nephritis.

\section{DECLARATIONS}

\section{Acknowledgement}

The authors thank Linyi People's Hospital, Linyi, Shandong Province, China, for providing funds for this work.

\section{Conflict of Interest}

No conflict of interest associated with this work.

\section{Contribution of Authors}

The authors declare that this work was done by the authors named in this article and all liabilities pertaining to claims relating to the content of this article will be borne by them.

\section{Open Access}

This is an Open Access article that uses a funding model which does not charge readers or their institutions for access and distributed under the terms of the Creative Commons Attribution License (http://creativecommons.org/licenses/by/ 4.0) and the Budapest Open Access Initiative (http://www.budapestopenaccessinitiative.org/rea d), which permit unrestricted use, distribution, and reproduction in any medium, provided the original work is properly credited.

\section{REFERENCES}

1. Khraishi MM. Experience with subcutaneous abatacept for rheumatoid arthritis: an update for clinicians. Ther Adv Musculoskelet Dis 2014; 6(5): 159-168.

2. Pieper J, Herrath J, Raghavan S, Muhammad $K$, Vollenhoven R, Malmstrom V. CTLA4-lg (abatacept) therapy modulates $T$ cell effector functions in autoantibody-positive rheumatoid arthritis patients. BMC Immunol 2013; 14: 34.

3. Picchianti DA, Rosado MM, Scarsella M, Germano V, Giorda E, Cascioli S, Laganà B, D'Amelio R, Carsetti $R$. Abatacept (cytotoxic $T$ lymphocyte antigen 4immunoglobulin) improves $B$ cell function and regulatory $T$ cell inhibitory capacity in rheumatoid arthritis patients non-responding to anti-tumour necrosis factor-a agents. Clin Exp Immunol 2014; 177(3): 630-644.

4. Mihara M, Tan I, Chuzhin Y, Reddy B, Budhai L, Holzer $A$, et al. CTLA4lg inhibits $T$ cell dependent B-cell maturation in murine systemic lupus erythematosus. $J$ Clin Invest 2000; 106(1): 91-101.

5. Khraishi MM. Experience with subcutaneous abatacept for rheumatoid arthritis: an update for clinicians. Ther Adv Musculoskelet Dis 2014; 6(5): 159-168.

6. Ursini F, Naty S, Russo E, Grembiale RD. Abatacept in psoriatic arthritis: Case report and short review. J Pharmacol Pharmacother 2013; 4(Suppl1): S29-S32.

7. Yu CC, Fornoni A, Weins A, Hakroush $S$, Maiguel D, Sageshima J, Chen L, Ciancio G, Faridi MH, Behr D et al. Abatacept in B7-1-positive proteinuric kidney disease. N Engl J Med 2013; 369(25): 2416-2423.

8. Reiser J, von GG, Loos M, Oh J, Asanuma K, Giardino L, et al. Induction of B7-1 in podocytes is associated with 
nephrotic syndrome. J Clin Invest 2004; 113(10): 13901397.

9. Kluger MA, Melderis S, Nosko A, Goerke B, Luig M, Meyer MC, Turner JE, Meyer-Schwesinger $C$, Wegscheid $C$ et al. Treg17 cells are programmed by Stat3 to suppress Th17 responses in systemic lupus. Kidney Int 2015 Oct 14.

10. Traitanon O, Gorbachev A, Bechtel JJ, Keslar KS, Baldwin WM, III, Poggio ED, et al. IL-15 induces alloreactive CD28(-) memory CD8 $T$ cell proliferation and CTLA4-Ig resistant memory CD8 T cell activation. Am J Transplant 2014; 14(6): 1277-1289.

11. Monti S, Breda S, Grosso V, Todoerti M, Montecucco C, Caporali $R$. Switching from Intravenous to Subcutaneous Formulation of Abatacept: Different Results in a Series of 21 Patients. J Rheumatol 2015; 42(10): 1993-1994.

12. Kremer JM, Genant HK, Moreland LW, Russell AS, Emery $P$, Abud-Mendoza $C$, et al. Effects of abatacept in patients with methotrexate-resistant active rheumatoid arthritis: a randomized trial. Ann Intern Med 2006; 144(12): 865-876

13. Westhovens $R$, Robles $M$, Ximenes $A C$, Nayiager $S$, Wollenhaupt J, Durez $P$, et al. Clinical efficacy and safety of abatacept in methotrexate-naive patients with early rheumatoid arthritis and poor prognostic factors. Ann Rheum Dis 2009; 68(12): 1870-1877.

14. Reggia R, Franceschini F, Tincani A, Cavazzana I. Switching from intravenous to subcutaneous formulation of abatacept: a single-center Italian experience on efficacy and safety. J Rheumatol 2015; 42(2): 193-195.

15. Ganta S, Paxton JW, Baguley BC, Garg S. Pharmacokinetics and pharmacodynamics of chlorambucil delivered in parenteral emulsion. Int $J$ Pharm 2008; 360(1-2): 115-121.

16. Tagne JB, Kakumanu S, Ortiz D, Shea T, Nicolosi RJ. A nanoemulsion formulation of tamoxifen increases its efficacy in a breast cancer cell line. Mol Pharm 2008; 5(2): 280-286

17. Tagne JB, Kakumanu S, Nicolosi RJ. Nanoemulsion preparations of the anticancer drug dacarbazine significantly increase its efficacy in a xenograft mouse melanoma model. Mol Pharm 2008; 5(6): 1055-1063.

18. Handa T, Saito H, Miyajima K. Phospholipid monolayers at the triolein-saline interface: production of microemulsion particles and conversion of monolayers to bilayers. Biochemistry 1990; 29(11): 2884-2890.

19. Maeda H, Matsumura Y. Tumoritropic and lymphotropic principles of macromolecular drugs. Crit Rev Ther Drug Carrier Syst 1989; 6(3): 193-210.

20. NRC [National Research Council]. 1996. Guide for the Care and Use of Laboratory Animals. 7th ed. Washington DC: National Academy Press.

21. Ott G, Barchfeld GL, Van NG. Enhancement of humoral response against human influenza vaccine with the simple submicron oil/water emulsion adjuvant MF59. Vaccine 1995; 13(16): 1557-1562.

22. Feng $X$, Gu F, Chen W, Liu Y, Wei H, Liu L, et al. Mizoribine versus mycophenolate mofetil or intravenous cyclophosphamide for induction treatment of active lupus nephritis. Chin Med J (Engl) 2014; 127(21): 37183723.

23. Scarpato $S$, Antivalle M, Favalli EG, Nacci F, Frigelli $S$, Bartoli $F$, et al. Patient preferences in the choice of antiTNF therapies in rheumatoid arthritis. Results from a questionnaire survey (RIVIERA study). Rheumatology (Oxford) 2010; 49(2): 289-294.

24. Patlolla RR, Vobalaboina V. Pharmacokinetics and tissue distribution of etoposide delivered in parenteral emulsion. J Pharm Sci 2005; 94(2): 437-445.

25. Chan TM, Tse KC, Tang CS, Mok MY, Li FK. Long-term study of mycophenolate mofetil as continuous induction and maintenance treatment for diffuse proliferative lupus nephritis. J Am Soc Nephrol 2005; 16(4): 1076-1084.

26. Karassa FB, Isenberg DA. Efficacy of mycophenolate mofetil in patients with diffuse proliferative lupus nephritis. N Engl J Med 2001; 344(5): 382-383.

27. Rovin BH, Furie R, Latinis K, Looney RJ, Fervenza FC, Sanchez-Guerrero J, et al. Efficacy and safety of rituximab in patients with active proliferative lupus nephritis: the Lupus Nephritis Assessment with Rituximab study. Arthritis Rheum 2012; 64(4): 12151226.

28. Merrill JT, Burgos-Vargas R, Westhovens R, Chalmers A, $D^{\prime} C r u z D$, Wallace $D J$, et al. The efficacy and safety of abatacept in patients with non-life-threatening manifestations of systemic lupus erythematosus: results of a twelve-month, multicenter, exploratory, phase $\mathrm{llb}$, randomized, double-blind, placebo-controlled trial. Arthritis Rheum 2010; 62(10): 3077-3087. 